Tersedia online di: http://ejournal-balitbang.kkp.go.id/index.php/JP
e-mail:jurnalpari@gmail.com
JURNAL PARI
Volume 5 Nomor 2 Desember 2019
p-ISSN: 2502-0730
e-ISSN : 2549-0133

\title{
PERANCANGAN SISTEM INFORMASI PREDIKSI PASANG SURUT BERBASIS ANDROID DI PUSAT RISET KELAUTAN DESIGNING ANDROID-BASED TIDAL PREDICTION INFORMATION SYSTEMS AT THE MARINE RESEARCH CENTER
}

\author{
Dani Saepuloh \\ Pusat Riset Kelautan, Badan Riset dan Sumber Daya Manusia Kelautan dan Perikanan, KKP \\ Jl. Pasir Putih 1 Ancol Timur, Jakarta Telp : (021) 64711583, Fax : (021) 64711654 \\ Diterima tanggal : 2 Agustus 2019 Diterima setelah perbaikan : 25 September 2019 \\ disetujui terbit : 15 November 2019
}

\begin{abstract}
ABSTRAK
Pasang surut air laut merupakan parameter yang sangat penting bagi navigasi di pelabuhan, Pusat Riset Kelautan, Marine \& Coastal Data Laboratory (MCDL) membuat prediksi pasang surut di 39 pelabuhan seluruh Indonesia. Penelitian ini bertujuan menghasilkan sistem informasi prediksi pasang surut berbasis android dengan menggunakan bahasa pemograman Java, Google Maps Api sebagai basemapnya dan data prediksi pasang surut yang dihasilkan oleh MCDL. Informasi yang ditampilkan dalam bentuk grafik dan data tabel untuk 14 hari kedepan (2 minggu), dengan resolusi temporal per jam dengan pemuktahiran (update) informasi per 14 hari. Dalam aplikasi android prediksi pasang surut (pasut) terdiri dari 4 menu yaitu Pelabuhan, Glosarium, About, Disclaimer. Menu Pelabuhan menampilan informasi nama pelabuhan perikanan. Menu Glosarium berisikan informasi daftar istilah pasang surut. Menu About berisikan informasi pemilik aplikasi yang bertujuan untuk pengguna dapat berinteraksi dengan pemilih aplikasi. Menu Disclaimer (penyanggahan) berisikan informasi bahwa informasi perkiraan pasut ini digunakan sebagai rujukan (referensi) ketinggian muka/paras air laut di lokasi Pelabuhan Perikanan untuk kepentingan operasi keluar dan masuknya kapal. Informasi tentang kedalaman batimetri dan kondisi dasar perairan lokasi tidak disediakan pada aplikasi ini.
\end{abstract}

KATA KUNCI : Prediksi Pasang Surut; Pasut; Android; Pusriskel; MCDL.

\begin{abstract}
Tide is a very important parameter for navigation in ports, the Center for Marine Research, Marine \& Coastal Data Laboratory (MCDL) makes tide predictions in 39 ports throughout Indonesia. This study aims to produce an Android-based tidal prediction information system using the Java programming language, Google Maps Api as its basemap and tidal prediction data generated by MCDL. Information displayed in graphical form and data tables for the next 14 days (2 weeks), with hourly temporal resolution with updated information per 14 days. In the tide prediction android application (tides) consists of 4 menus namely Port, Glossary, About, Disclaimer. The Port menu displays information on the name of the fishing port. The Glossary menu contains tidal term glossary information. The About menu contains application owner information that aims for users to interact with the application chooser. The Disclaimer Menu contains information that this tidal estimated information is used as a reference (reference) for sea level / sea level at the Fishery Port location for the purpose of operating in and out of ships. Information about the bathymetry depth and the bottom waters of the location is not provided in this application.
\end{abstract}

KEYWORDS: Tidal Prediction; Tidall; Android; Pusriskel; MCDL. 


\section{PENDAHULUAN}

Pasang surut air laut merupakan parameter yang sangat penting bagi navigasi di pelabuhan, Pusat Riset Kelautan, Marine \& Coastal Data Laboratory (MCDL) membuat prediksi pasang surut di 39 pelabuhan seluruh indonesia. Penelitian ini bertujuan menghasilkan sistem informasi prediksi pasang surut berbasis android dengan menggunakan bahasa pemograman Java, Google Maps Api sebagai basemapnya dan data prediksi pasang surut yang dihasilkan oleh MCDL. Informasi yang ditampilkan dalam bentuk grafik dan data tabel untuk 14 hari kedepan (2 minggu), dengan resolusi temporal per jam dengan pemuktahiran (update) informasi per 14 hari. Dalam aplikasi android prediksi pasang surut (pasut) terdiri dari 4 menu yaitu Pelabuhan, Glosarium, About, Disclaimer. Menu Pelabuhan menampilan informasi nama pelabuhan perikanan. Menu Glosarium berisikan informasi daftar istilah pasang surut. Menu About berisikan informasi pemilik aplikasi yang bertujuan untuk pengguna dapat berinteraksi dengan pemilih aplikasi. Menu Disclaimer (penyanggahan) berisikan informasi bahwa informasi perkiraan pasut ini digunakan sebagai rujukan (referensi) ketinggian muka/paras air laut di lokasi Pelabuhan Perikanan untuk kepentingan operasi keluar dan masuknya kapal. Informasi tentang kedalaman batimetri dan kondisi dasar perairan lokasi tersebut tersebut tidak disediakan pada aplikasi ini.

Info prakiraan pasut ini adalah hasil peramalan menggunakan 11 Komponen Harmonik, yakni 4 Komponen Semidiurnal (M2, S2, N2, K2), 4 Komponen Diurnal (K1, O1, P1, Q1), dan 3 Komponen turunan dari Semidiurnal (MF, MM, M4). Seluruh komponen tersebut adalah turunan dari data satelit altimetry Topex/Poseidon (Egbert \& Erofeeva, 2002). Peramalan dilakukan terhadap koordinat-koordinat Pelabuhan Perikanan yang dikelola oleh Direktorat Jenderal Perikanan Tangkap, Kementerian Kelautan dan Perikanan Republik Indonesia (DGCF, 2009). Sedangkan verifikasi hasil peramalan terhadap data pengukuran/observasi telah dilakukan dengan hasil cukup memuaskan (Ramdhan, 2011; Pranowo \& Wirasantosa, 2011).

\section{METODOLOGI}

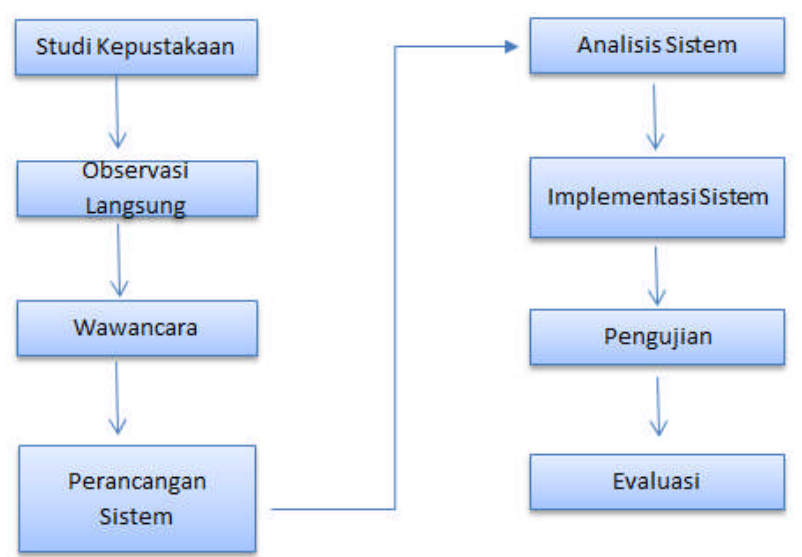

Gambar 1. Tahapan langkah dalam penelitian ini

\section{HASIL DAN PEMBAHASAN}

\section{A. Langkah Pembangunan Sistem}

\section{Gambaran Umum Sistem}

Sistem informasi prediksi pasang surut dibangun dengan berbasiskan Android dengan menggunakan bahasa pemrograman Java dan dipadukan dengan database MySQL. Jenis pemrograman Java yang digunakan pada aplikasi ini adalah pemrograman berorientasi objek. Peta menggunakan Google Maps Api untuk mengetahui lokasi pelabuhan berada. Halaman pada Menu Utama meliputi beberapa bagian antara lain header, menu, content serta beberapa menu variasi tambahan guna mempercantik aplikasi. Header berisikan logo dan keterangan tentang nama aplikasi, menu berisikan 4 pilihan menu yaitu Pelabuhan, Glosarium, About, Disclaimer.

\section{B. Implementasi Perangkat Keras dan Perangkat Lunak}

\section{Perangkat Keras (Hardware)}

Perangkat keras yang digunakan untuk pembangunan aplikasi ini adalah sebuah komputer dengan spesifikasi:

a. Processor Intel(R) Xeon(R) CPUE5620 @2.4 GHz $2.4 \mathrm{GHz}$

b. Hardisk 1 TB 5400-rpm

c. RAM 12 GB

d. VGA Intel Graphics Media Accelerator (GMA) HD 


\section{Perangkat Lunak (Software)}

Piranti lunak yang digunakan pada pembangunan aplikasi ini:

a. Microsoft Windows 7 Professional Service Pack 1, 32 bit sebagai platform sistem operasi dalam pengembangan aplikasi

b. XAMPP Web Server Version 1.7.3 sebagai webserver

c. MySQL Database Version 5.1.41 sebagai DBMS

d. phpMyAdmin Version 3.2.4 sebagai Database Manager.

e. Android Studio coding (menuliskan source code Java for Android)

f. Aplikasi Adobe Potoshop CS6 untuk mendesain tampilan aplikasi

\section{Hasil Implementasi Antarmuka}

\section{Splash Screen (Halaman Pembuka)}

Halaman yang akan ditampilkan pertama kali ketika user membuka aplikasi sistem informasi prediksi pasang surut. Halaman Splash Screen ini berisi elemen kontrol grafis yang terdiri dari jendela yang berisi gambar, logo, dan versi perangkat lunak saat ini. Layar splash biasanya muncul saat program sedang diluncurkan.

\section{Kode Pada Halaman Splash Screen splashscreen.java}

Kode program ini berfungsi untuk manarik (load) informasi dari server dan akan otomatis masuk kehalaman menu utama (home).

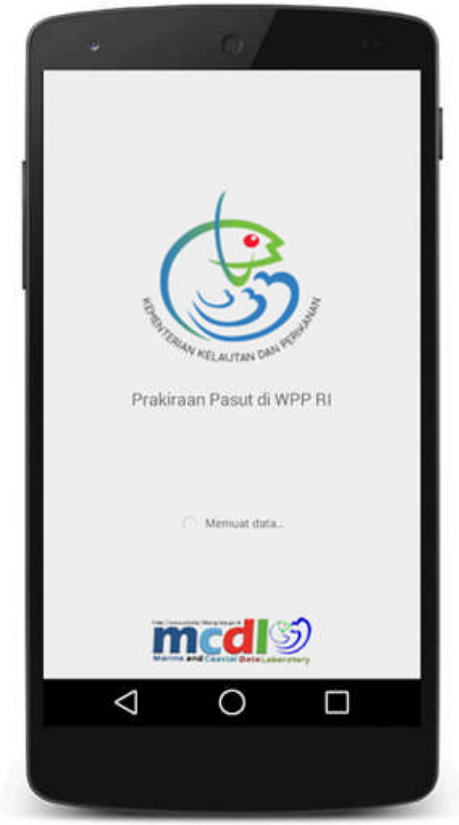

Gambar 2. Halaman Splash Screen package com.p3sdlp.pasut;

import java.util.ArrayList;

import java.util.HashMap;

import org.json.JSONArray;

import org.json.JSONException;

import org.json.JSONObject;

import com.p3sdlp.pasut.pustaka.DBHelper;

import com.p3sdlp.pasut.pustaka.ServiceHandler;

import android.support.v7.app.ActionBarActivity;

import android.util.Log;

import android.view. View;

import android.widget.LinearLayout;

import android.app.ActivityManager;

import android.app.ActivityManager. RunningService Info;

import android.app.AlertDialog;

import android.app.NotificationManager;

import android.content.Context;

import android.content.Dialog Interface;

import android.content.Intent;

import android.os.AsyncTask;

import android.os.Bundle;

public class Splash extends ActionBarActivity \{

JSONArray pelabuhan = null;

ArrayList $<$ HashMap $<$ String, String $>>$

daftarpelabuhan:

HashMap $<$ String, Integer $>$ nNotip $=$ new

HashMap<String, Integer $>()$;

Intent notip = new

Intent(Notification.class.getName());

Boolean anydata = false;

LinearLayout loading;

private static final String TAG_PELABUHAN

= "pelabuhan";

private static final String TAG_ID = "id";

private static final String TAG_TITLE = "title"; private static final String TAG LAT = "metakey";

private static final String TAG_LNG = "metadesc";

private static final String TAG_DB = "station"; private static final String

TAG_UNREAD_NOTIF = "unreadnotification";

@Override

protected void onCreate(Bundle savedInstanceState) \{ 
super.onCreate(savedlnstanceState);

setContentView(R.layout.activity_splash);

loading

(LinearLayout)findViewByld(R.id.LinearLayout3);

loading.setVisibility(View.INVISIBLE);

$$
\text { daftarpelabuhan = new }
$$

ArrayList $<$ HashMap $<$ String, String $>>()$;

new GetData().execute();

\}

private

boolean

isNotifServiceRunning(Class $<$ ? > serviceClass) \{

ActivityManager manager $=$

( $\mathrm{A}$ c $\mathrm{t}$ i $\mathrm{v}$ i $\mathrm{t}$ y $M$ a $n$ a $g$ e $r$ ) getSystemService(Context.ACTIVITY_SERVICE); for (RunningServicelnfo service : manager.getRunningServices(Integer.MAX_VALUE)) \{ (seniceClass.getName().equals(senice.senvice.getClassName())) \{

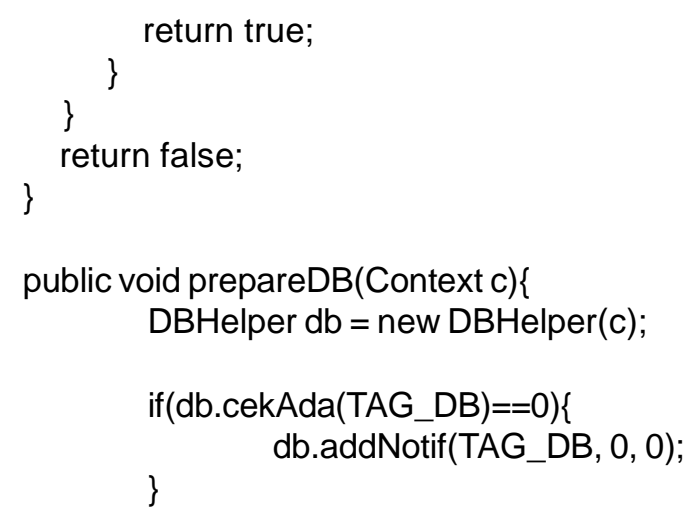

$==0)\{$

db.addNotif(daftarpelabuhan.get(i).get(TAG_TITLE), 0, Integer.valueOf(daftarpelabuhan.get(i).get(TAG_ID))); \}else\{

db.updateNotifValue(daftarpelabuhan.get(i).get(TAG_TITLE), Integer.valueOf(daftarpelabuhan.get(i).get(TAG_ID)));

NotificationManager notif = (NotificationManager)c.getSystemSenice(Context.NOTIFICATION_ SERVICE);

$$
\text { \} notif.cancel(100); }
$$

private class GetData extends AsyncTask<Void, Void, Void $>\{$

\section{@Override} protected void onPreExecute( $)\{$ super.onPreExecute();

loading.setVisibility(View.VISIBLE);

$$
\text { \} }
$$

@Override

protected Void

dolnBackground(Void... arg0) \{

ServiceHandler();

ServiceHandler sh $=$ new

$$
\text { String url = "http:// }
$$

p3sdlp.litbang.kkp.go.id/includes/appdaftarPelabuhan.php?f=list";

$$
\text { String jsonstr= }
$$
sh.makeServiceCall(url, ServiceHandler.GET);

$$
\begin{gathered}
\text { if (jsonStr != null) }\{ \\
\text { try }\{
\end{gathered}
$$

JSONObject jsonObj = new JSONObject(jsonStr);

= jsonObj.getJSONArray(TAG_PELABUHAN); pelabuhan

$0 ; \mathrm{i}<$ pelabuhan.length ()$; \mathrm{i}++)\{$ for (int $\mathrm{i}=$ JSONObject c = pelabuhan.getJSONObject(i);

String id = c.getString (TAG_ID);

String title $=$ c.getString $($ TAG_TITLE); 
String lat = c.getString $($ TAG_LAT $)$;

String Ing = c.getString (TAG_LNG);

HashMap $<$ String, String $>$ data = new HashMap $<$ String, String $>()$;

data.put(TAG_ID, id);

data.put(TAG_TITLE, title);

data.put(TAG_LAT, lat);

data.put(TAG_LNG, Ing);

daftarpelabuhan.add(data);

(JSONException e) \{

catch

e.printStackTrace();

$$
\text { \} else }\{
$$$$
\text { anydata }=\text { true; }
$$$$
\text { \} catch }
$$

Log.e("ServiceHandler”, “Couldn't get any data from the url");

\}

return null;

$$
\text { \} }
$$

@Override

result) \{

protected void onPostExecute(Void

super.onPostExecute(result);

loading.setVisibility(View.INVISIBLE); if(anydata) \{

prepareDB(getApplicationContext()); Intent main $=$ new

Intent(Splash.this, MainActivity.class);

main.putExtra("station", daftarpelabuhan);

finish(); \}else\{
AlertDialog.Builder(Splash.this)

.setMessage(“Sambungan data bermasalah.”)

.setPositiveButton("Coba lagi”,

new DialogInterface.OnClickListener() \{

public void onClick(DialogInterface dialog,

$$
\text { int which) \{ }
$$

dialog.cancel();

new GetData().execute();

\}

.setNegativeButton(“Keluar”, new DialogInterface.OnClickListener() \{

dialog, public void onClick(DialogInterface int which) \{ dialog.cancel(); finish();

\}).

setCancelable(false).show();

\}

\}

\section{Halaman Menu Utama}

Setelah menu Splash Screen yang akan ditampilkan menu utama (home), yang memberikan informasi lokasi pelabuhan yang ditampilkan melalui peta interaktif dan terdapat 4 menu dibawahnya yaitu Pelabuhan, Glosarium, About, Disclaimer. Menu utama dapat dilihat pada gambar 3 


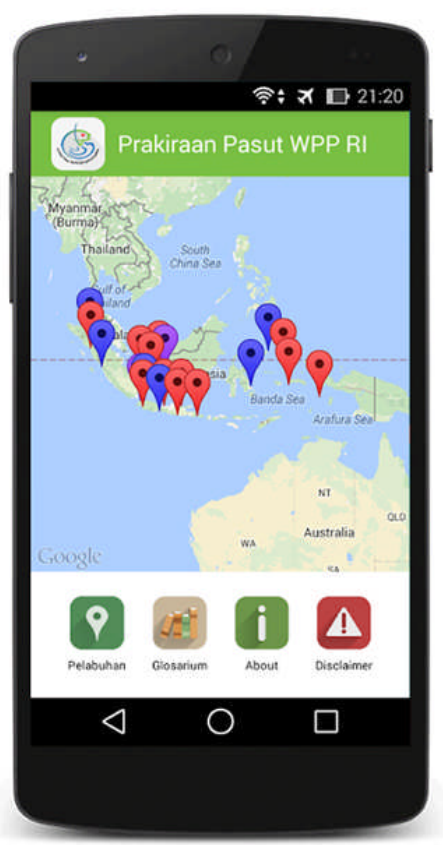

Gambar 3. Halaman Menu Utama (home)

MainActivity.java

kode file ini berfungsi menampilkan sebaran pelabuhan dalam peta

package com.p3sdlp.pasut;

import java.util.ArrayList;

import java.util.HashMap;

import com.google.android.gms.maps. CameraUpdateFactory;

import com.google.android.gms.maps.GoogleMap;

i $m$ p $\quad 0 \quad r$ t com.google.android.gms.maps.GoogleMap.OnInfo WindowClickListener;

import com.google.android.gms.maps.GoogleMap.On MarkerClickListener;

import com.google.android.gms.maps.OnMap ReadyCallback;

import com.google.android.gms.maps.SupportMap Fragment;

import com.google.android.gms.maps.model.Bitmap Descriptor Factory;

import com.google.android.gms.maps.model.Camera Position;

import com.google.android.gms.maps.model.LatLng; import com.google.android.gms.maps.model.Marker; i $m \quad p \quad l l l$ com.google.android.gms.maps.model.MarkerOptions; import com.p3sdlp.pasut.pustaka.DBHelper;

import android.annotation.SuppressLint; import android.content.Intent; import android.os.Bundle; import android.os. Handler; import android.support.v7.app.ActionBarActivity; import android.support.v7.widget.Toolbar; import android.view. View; import android.widget.ImageButton;

\section{@SuppressLint(“NewApi”)}

public class MainActivity extends ActionBarActivity implements

\section{OnMarkerClickListener}

On MapRead y C a ll b a ck, private Toolbar mToolbar; private SupportMapFragment mapFragment; private MarkerOptions option;

private static final String TAG_ID = "id"; private static final String TAG_TITLE = "title"; "metakey", private static final String TAG_LAT = "metadesc";

private static final String TAG_LNG = private static final String TAG_DB = "station"; private static final String TAG_PPS = "PPS"; private static final String TAG_PPN = "PPN"; private static final String TAG_PPI = "PPI"; private static final String TAG_CPP = "CPP"; private static final String TAG_PPP = "PPP";

final Handler handler = new Handler();

Runnable refresh; station;

private ArrayList $<$ HashMap $<$ String, String $>>$

ImageButton InkPelabuhan;

Boolean adaYangBaru;

@Override

protected void onCreate(Bundle savedlnstanceState) \{

super.onCreate(savedlnstanceState);

setContentView(R.layout.activity_main);

Intent intent $=$ getIntent () ; station

(ArrayList<HashMap $<$ String, String $>>$ ) intent

.getSerializableExtra("station");

refresh $=$ new Runnable ()\{

@Override

public void run() \{

cekPembaruan();

handler.postDelayed(this, 2000); 


$$
\}
$$

handler.postDelayed(refresh, 2000);

R.drawable.ic_launcher;

$$
\text { Integer iconnya }
$$$$
\text { InkPelabuhan }=(\text { ImageButton })
$$

findViewByld(R.id.btnPelabuhan);

$$
\text { mToolbar= }
$$

(Toolbar)

findViewByld(R.id.toolbar_actionbar); setSupportActionBar(mToolbar);

getSupportActionBar().setDisplayShowHomeEnabled(true);

$$
\text { getSupportActionBar().setlcon(iconnya); }
$$$$
\text { getSupportActionBar().setTitle(" }
$$

Prakiraan Pasut WPP Rl”);

$$
\text { mapFragment }
$$

( $S$ u p p o r t M a p F r a g m e $n t$ ) getSupportFragmentManager()

.findFragmentByld(R.id.map);

$$
\text { \} }
$$

$$
\text { mapFragment.getMapAsync(this); }
$$

private void clearUpdate(String target)\{

DBHelper $\mathrm{db}=$ new DBHelper(this); if $($ db.cekNotif $($ target $)==1)\{$

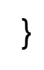

public void cekPembaruan() \{

DBHelper $\mathrm{db}=$ new DBHelper(this); adaYangBaru = false;

for(int $\mathrm{x}=0 ; \mathrm{x}<$ station.size ()$; \mathrm{x}++)\{$

(db.cekNotifByID(Integer.valueOf(station.get(x).get(TAG_ID))) $==1)\{$

true;

$$
\text { adaYangBaru = }
$$

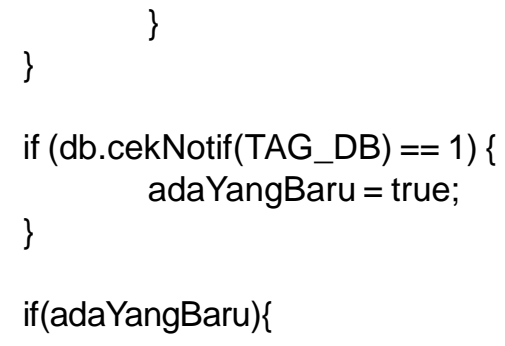

InkPelabuhan.setImageResource(R.drawable.ic_place main_new);

\section{\}else if(!adaYangBaru)\{}

InkPelabuhan.setImageResource(R.drawable.ic_place main);

\}

public void kePelabuhan(View v) \{

DBHelper $\mathrm{db}=$ new DBHelper(this); if $($ db.cekNotif(TAG_DB $)==1)\{$ db.updateNotif(TAG_DB, 0);

\} Intent listpelabuhan $=$ new Intent(getApplicationContext(),

DaftarPelabuhan.class);

station);

listpelabuhan.putExtra("station", startActivity(listpelabuhan);

\}

$$
\text { public void keGlosarium(View v) \{ }
$$
Intent glosari = new Intent(getApplicationContext(), Glosarium.class); startActivity(glosari);

\}

$$
\text { public void keAbout(View v) \{ }
$$
Intent about = new Intent(getApplicationContext(), SinglePage.class); about.putExtra("page", "about"); startActivity(about);

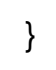

public void keDisclaimer(View v) \{ Intent disclaimer $=$ new Intent(getApplicationContext(),

"disclaimer");

$$
\begin{array}{r}
\text { SinglePage.class); } \\
\text { disclaimer.putExtra("page", }
\end{array}
$$

startActivity(disclaimer);

public double fix2digit(String value) \{ double valDouble =

Double.parseDouble(value) * 100; int vallnt $=$ (int) valDouble; valDouble = vallnt / 100.0; return valDouble;

\}

public boolean onMarkerClick(Marker marker)

\{ Intent listtahun = new Intent(getApplicationContext(), DaftarTahun.class); 
listtahun.putExtra("pelabuhan", marker.getTitle().trim().replaceAll("IIs+", "')); startActivity(listtahun);

return true;

$$
\text { \} }
$$

@Override

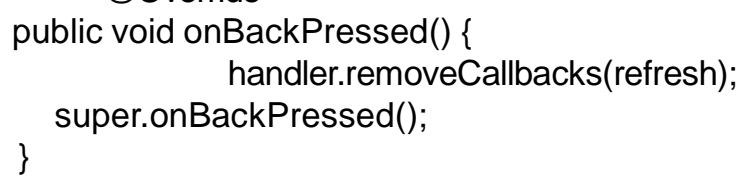

@Override

public void onMapReady(GoogleMap map) \{ obj++) \{ for (int obj = 0; obj < station.size();

MarkerOptions();

$$
\text { option = }
$$

option.position (new

LatLng(fix2digit(station.get(obj).get(TAG_LAT)), fix2digit(station. get(obj).get(TAG_LNG))))

.title(station.get(obj).get(TAG_TITLE)) .snippet(“Tap here.”);

if(station.get(obj).get(TAG_TITLE).substring (0, 3).equalsignoreCase(TAG_PPS) \{

option.icon(BitmapDescriptorFactory.defaultMarker(Bitmap DescriptorFactory.HUE_BLUE));

$$
\text { \} e I s e }
$$

if(station.get(obj).get(TAG_TITLE).substring $(0$, 3).equalslgnoreCase(TAG_PPN) \{

option.icon(BitmapDescriptorFactory.defaultMarker(Bitmap DescriptorFactory.HUE_RED));

\} e l s e
if(station.get(obj).get(TAG_TITLE).substring $(0$, 3).equalslgnoreCase(TAG_PPI) $)\{$

option.icon(BitmapDescriptorFactory.defaultMarker(Bitmap DescriptorFactory.HUE_GREEN));

$$
\text { \} e I } s \quad e
$$

if(station.get(obj).get(TAG_TITLE).substring ( 0 ,

3).equalslgnoreCase(TAG_CPP))\{

option.icon(BitmapDescriptorFactory.defaultMarker(Bitmap DescriptorFactory.HUE_YELLOW));

$$
\text { \} e l s e }
$$

if(station.get(obj).get(TAG_TITLE).substring $(0$,

3).equalslgnoreCase(TAG_PPP))\{
option.icon(BitmapDescriptorFactory.defaultMarker(Bitmap

DescriptorFactory.HUE_VIOLET));

\}else\{

option.icon(BitmapDescriptorFactory.defaultMarker(Bitmap DescriptorFactory.HUE_MAGENTA));

\}

map.addMarker(option);

.title(station.get(obj).get(TAG_TITLE)).snippet(“Tap here."));

\section{\}}

map.setOnInfoWindowClickListener(new

OnInfoWindowClickListener() \{

@Override

public

void

onInfoWindowClick(Marker marker) \{

// TODO Auto-

generated method stub

clearUpdate(marker.getTitle()); Intent listtahun $=$
Intent(getApplicationContext(), DaftarTahun.class);

list tahun.putExtra( "pelabuhan", marker.getTitle().trim().replaceAll(“Ils+", “"));

listtahun.putExtra("from", "main");

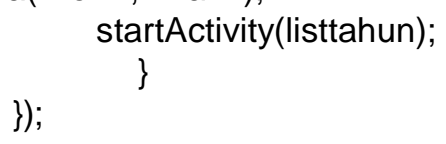

CameraPosition cameraPosition $=$ new CameraPosition.Builder()

t t a rget ( n e w

LatLng(-2.5, 118)).zoom(3).build();

map.moveCamera(CameraUpdateFactory.newCamera

Position(cameraPosition));

\}

\section{Halaman Pelabuhan}

Menampilkan menu Pelabuhan yang berisi informasi nama pelabuhan perikanan. Tampilan bisa di lihat pada gambar 3 di bawah ini. 


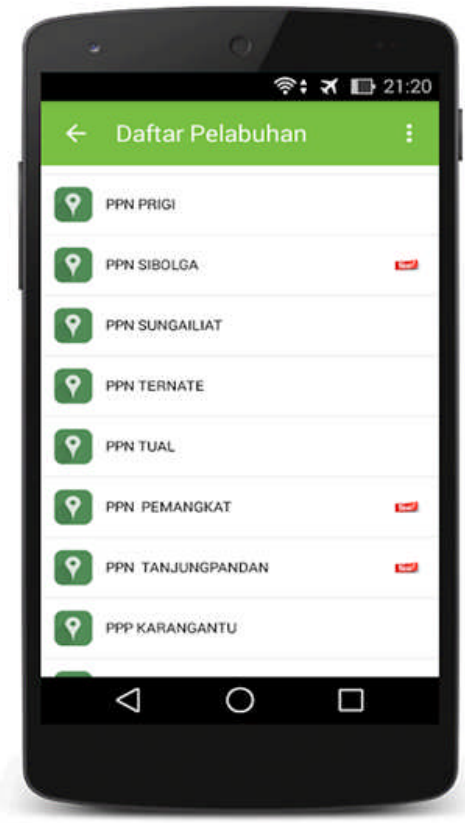

Gambar 3. Halaman Pelabuhan

\section{pelabuhan.java}

file ini berfungsi untuk meload data pelabuhan.

package com.p3sdlp.pasut;

public class Pelabuhan \{

public String title;

public Boolean baru;

public Pelabuhan(String title, Boolean baru) \{

this.title = title;

\}

this.baru = baru;

\section{Halaman Prediksi Pasang Surut}

Halaman ini menampilkan informasi yang ditampilkan dalam bentuk grafik dan data tabel untuk 14 hari kedepan (2 minggu), dengan resolusi temporal per jam dengan pemuktahiran (update) informasi per 14 hari pridiksi pasang surut bisa dilihat pada gambar 4.

\section{Halaman Glosarium}

Menampilkan menu Glosarium berisikan informasi daftar istilah pasang surut. Tampilan bisa di lihat pada gambar 5 di bawah ini:

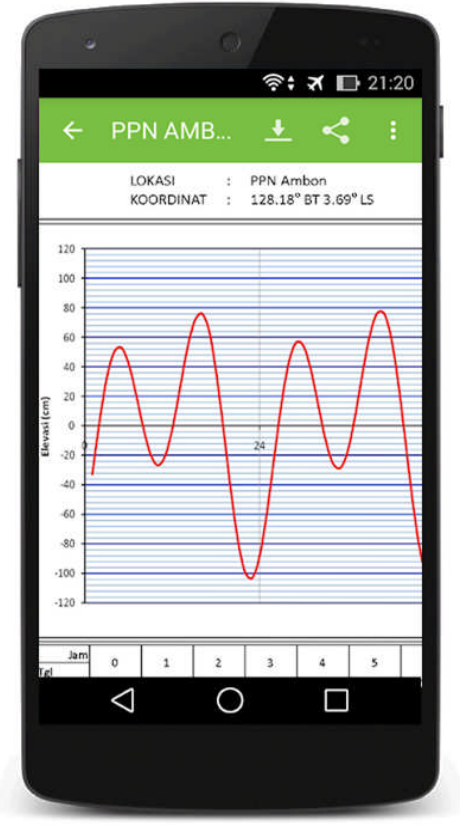

Gambar 4. Halaman Prediksi Pasang Surut.

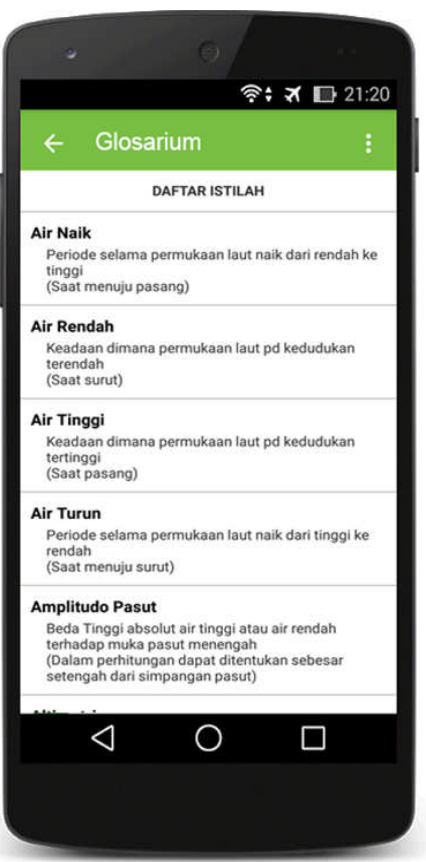

Gambar 5. Halaman Glosarium

6. Halaman About

Menampilkan menu About berisikan informasi pemilik aplikasi yang bertujuan untuk pengguna dapat berinteraksi dengan pemilik aplikasi.Tampilan bisa di lihat pada gambar 6 di bawah ini. 


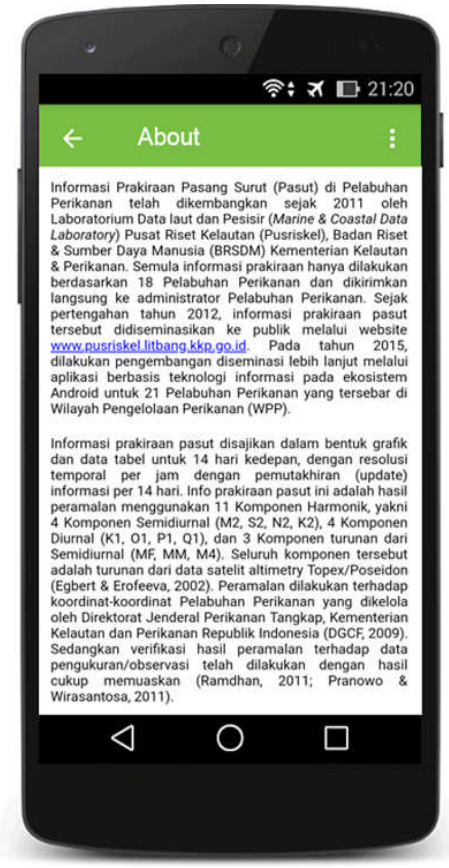

Gambar 6. Halaman About

\section{Halaman Disclaimer}

Menampilkan menu disclaimer berisikan informasi bahwa informasi pasut dihasilkan oleh MCDL, segala penyalahgunaan penggunaan informasi yang ada dalam aplikasi ditanggung sendiri. Tampilan bisa di lihat pada gambar 7 di bawah ini:

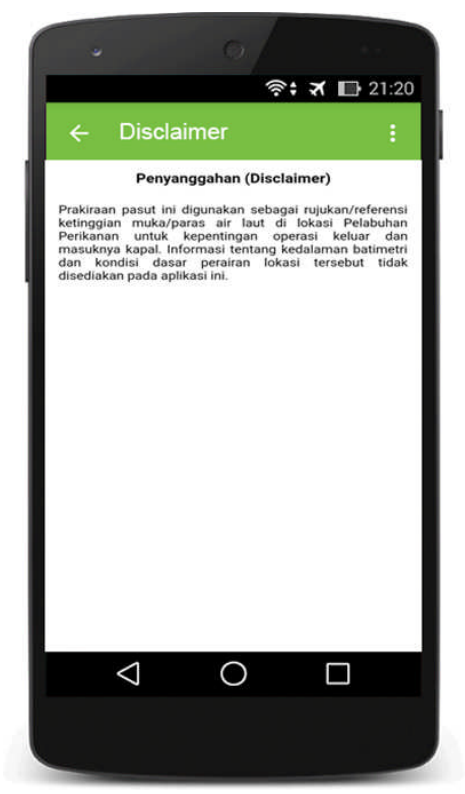

Gambar 7. Halaman Disclaimer

\section{Pengujian Sistem}

Setelah tahap implementasi hasil rancangan sistem dilakukan, maka tahap selanjutnya adalah melakukan pengujian terhadap sistem. Pengujian terhadap sistem dilakukaan dengan uji fungsionalitas menggunakan metode Black-Box Test.

\section{Black-Box Test}

Black-Box Test yaitu pengujian yang berfokus pada persyaratan fungsional suatu piranti lunak dengan membuat himpunan kondisi input yang akan melatih seluruh syarat-syarat fungsional system (Pressman, 2010). Tabel di bawah ini merupakan hasil uji coba yang telah dilakukan terhadap sistem, berupa deskripsi fungsi-fungsi dari menu pada aplikasi serta menunjukkan kesesuaian fungsi yang dihasilkan ketika dilakukan pengetesan. Dari hasil uji coba tersebut dapat dilihat bahwa semua fungsi yang diharapkan telah dapat tercapai, ditandai dengan keterangan 'Berhasil' pada kolom 'Hasil Aktual'.

\section{E. Evaluasi Sistem}

Dalam pembangunan sebuah sistem, terkadang tidak semua hal yang telah direncanakan, dianalisis dan dirancang dapat diimplementasikan dengan baik. Berikut akan dijelaskan beberapa hal baik yang berhasil di implementasikan pada sistem (kelebihan sistem) maupun yang kurang berhasil diimplementasikan pada sistem (kekurangan sistem).

1. Kelebihan Sistem

a. Semua masyarakat dapat menggunakan Sistem Informasi Prediksi Pasang Surut Berbasis Android, secara gratis.

b. Tampilan aplikasi yang dibuat semudah mungkin.

2. Kekurangan Sistem

a. Sistem aplikasi ini belum adanya menu admin (backend) data ditampilkan langsung dari website http://pusriskel.litbang.kkp.go.id/

b. Belum kompatibel untuk Oparating System Applae (IOS). 
Tabel 4.1 Black-Box Test

\begin{tabular}{|c|c|c|c|c|}
\hline No & $\begin{array}{l}\text { Nama } \\
\text { Fungsi }\end{array}$ & Deskripsi & Hasil yang Diharapkan & Hasil Aktual \\
\hline 1. & $\begin{array}{l}\text { Splash } \\
\text { Screen }\end{array}$ & $\begin{array}{l}\text { Halaman yang akan } \\
\text { ditampilkan pertama kali ketika } \\
\text { user membuka aplikasi sistem } \\
\text { informasi prediksi pasang surut }\end{array}$ & $\begin{array}{l}\text { Menampilkan halaman Splash } \\
\text { Screen }\end{array}$ & Berhasil \\
\hline 2. & $\begin{array}{l}\text { Menu } \\
\text { Utama }\end{array}$ & $\begin{array}{l}\text { Menampilkan menu utama } \\
\text { (home), yang memberikan } \\
\text { informasi lokasi pelabuhan } \\
\text { yang ditampilkan melalui peta } \\
\text { interaktif dan terdapat } 4 \text { menu } \\
\text { dibawahnya yaitu Pelabuhan, } \\
\text { Glosarium, About, Disclaimer. }\end{array}$ & $\begin{array}{l}\text { Menampilkan menu utama, } \\
\text { Informasi lokasi pelabuhan }\end{array}$ & Berhasil \\
\hline 3. & Pelabuhan & $\begin{array}{l}\text { Menampilkan menu Pelabuhan } \\
\text { yang berisi informasi nama } \\
\text { pelabuhan perikanan }\end{array}$ & Menampilkan data Pelabuhan & Berhasil \\
\hline 4 & $\begin{array}{l}\text { Prediksi } \\
\text { Pasang } \\
\text { Surut }\end{array}$ & $\begin{array}{l}\text { Menampilkan informasi yang } \\
\text { ditampilkan dalam bentuk grafik } \\
\text { dan data tabel untuk } 14 \text { hari } \\
\text { kedepan ( } 2 \text { minggu), dengan } \\
\text { resolusi temporal per jam } \\
\text { dengan pemuktahiran ( update) } \\
\text { informasi per } 14 \text { hari pridiksi } \\
\text { pasang surut }\end{array}$ & $\begin{array}{l}\text { Menamfilkan informasi Prediksi } \\
\text { Pasang Surut dalam bentuk grafik }\end{array}$ & Berhasil \\
\hline
\end{tabular}

\section{SIMPULAN}

Berdasarkan hasil dari analisa, perancangan, dan implementasi, maka didapatkan beberapa kesimpulan sebagai berikut :

1. Hasil penelitian telah membangun Sistem Informasi Prediksi Pasang Surut Berbasis Android.

2. Informasi prediksi pasang surut di tampilkan dalam bentuk grafik.

3. Informasi prediksi pasang surut untuk 14 hari kedepan (2 minggu), dengan resolusi temporal per jam dengan pemuktahiran (update) informasi per 14 hari.

\section{DAFTAR PUSTAKA}

https://developer.android.com/guide di akses pada tanggal 24 Oktober 2019

DJCF, 2009. Indonesian Fishing Ports 2009. Guideline Book. Directorat General of Capture
Fisheries, Ministry of Marine Affairs \& Fisheries of The Republic of Indonesia \& Japan International Cooperation Agency.pp.113.

Egbert, G.D. \& S.Y. Erofeeva, 2002.Efficient Inverse Modeling of Barotropic Ocean Tides. Am. Met. Soc., (19): 183-204.

Pranowo, W.S. \& S. Wirasantosa. 2011. Tidal regims of Arafura \& Timor Seas. Journal of Marine Research in Indonesia 36(1): 21-28.

Pressman, Roger S. (2010). Software Engineering: a practioner's approach. McGraw-Hill, New York.

Ramdhan, M., 2011. Komparasi Hasil Pengamatan Pasang Surut di Perairan Pulau Pramuka dan Kabupaten Pati dengan Prediksi Pasang Surut Tide Model Driver. J. Segara, Vol.7, No.1, p.1-10. 